\title{
Reflection on the Massive Blast of Tianjin from the Perspective of Government Emergency Management
}

\author{
Jie $\mathrm{Gu}^{1, \mathrm{a}}$, Quanliang Mei ${ }^{1, \mathrm{~b}}$ and Song Mei ${ }^{1,2, \mathrm{c}}$ \\ ${ }^{1}$ School of Literature, Law and Economics, Wuhan University of Science and Technology, P. R. \\ China; \\ ${ }^{2}$ Hubei Institute of Administrator, P. R. China. \\ agujie0101@126.com, bmeior1996@163.com, 'cmeisong@126.com
}

\begin{abstract}
The massive blast of Tianjin on August 12ed is one of the largest safety production and fire protection incidents since the establishment of China, which caused numerous deaths and injuries, as well as great economic losses. It also reflects many problems of the government's emergency response in this accident, such as lacking of major pre-accident safety precautions, dealing with things in panic, blind and unscientific, after disposal loopholes. All alert the government that emergency management process should adhere to advance prevention, the principle of people-oriented, unified command, scientific rescue and response according to law in and after the accident, and take a professional road on building fire team.
\end{abstract}

Keywords: Tianjin blast; Fire; Emergent accident; Government emergency management.

\section{Introduction}

At 23:30 on August 12, 2015, in Tianjin Binhai New Area in Tianjin Tanggu Development Zone, Dongjiang Bonded Port Ruihai International Logistics Co., Ltd.' dangerous goods warehouse exploded, resulting in a total of 165 deaths, among which 24 were public security firefighters, 75 Tianjin Port firefighters, 11 police, 55 other personnel [1]. This explosion is a massive safety accident, also the largest fire accident since the founding of China. As an emergent incident, the local government where Ruihai Company located experienced a real test. There were many problems worthy of reflection in the emergency management of government.

\section{Problems in the Emergency Management of Government}

10 years has passed since the implementation of Emergent Accident Law in November 1, 2007, and specific implementation methods have been formulated in local governments. After the two major natural disasters in 2008, namely, the southern snow disaster and the earthquake in Wenchuan, the emergency management awareness and capacity of all levels of government have been increased remarkably. However, the Tianjin blast exposes many problems in the emergency management of government.

\subsection{Stepping on the red line of the Safety Prevention}

Setting a certain distance is one of the important measures to prevent accidents caused by secondary disasters. It has been clearly defined in the State Department's Dangerous Chemical Safety Regulations that the safe distance from dangerous chemicals warehouse and surrounding buildings is 1,000 meters, but, around the explosion point within 1,000 meters, there are more than 5,600 households. Harbour City (also known as "Shimizu Island") is a real estate developed by Vanke Group and the Tianjin Port together, lived by nearly 3,000 people, only 600 meters from the scene of the explosion. The Ruihai International Company, as the storage of hazardous chemicals, is so unscrupulous and inexcusable that it acquires interests regardless of safety as well as state laws and regulations, walking a fine line on a safe distance. The relevant government authorities and regulators also neglect national security laws and regulations, which is also unforgivable. Among them, Tianjin Port, Tianjin Transportation Commission as the management institution of hazardous chemicals industry department, give illegal issuance of business licenses, although knowing that Ruihai 
company does not have hazardous chemicals business qualifications, and conducts illegal business activities, which completely ignored safety supervision. In addition, relevant officials in Tianjin Binhai New Area Planning and Land Resources Bureau know that Ruihai company's storage location violates safety regulations, but still approve the company's illegal storage planning of dangerous chemicals business without strict examination and inspection. Tianjin Administration of Production Safety Supervision and Administration of Production Safety Supervision of the Binhai New Area did not exercise timely examination and punishment to Ruihai Company which has security risks and illegal business problem. Tianjin Xingang Customs officers responsible for the import and export of hazardous chemicals are irresponsible in the work of the regulatory activities, opening a green channel for disqualified Ruihai Company, indulging Ruihai company's illegal business activities. Tianjin Port (Group) Company laced management and did not supervise and correct security risks and illegal business problem in Ruihai Company. All fully demonstrates that, it is as a department security management is to disregard of safety precautions, national security laws and regulations, treading the red line in the safety prevention and management of security management department are the e most important human factors causing the explosion.

\subsection{Showing Blindness in Security Emergency}

The first fire alert was on 22:50, 12 August 2015, while the first explosion occurred at 23:34:06, local magnitude ML of about 2.3, equal to 3 tons TNT. The second explosion occurred 30 seconds later, local magnitude ML of about 2.9, a significant 2 tons TNT. Tianjin Port police fire brigade first arrived, followed by Tianjin Port Fire Brigade, two fire fight trucks of Eight Street Detachment and four fire fighting trucks of SWAT team before the first two explosions. After the two explosions, Tianjin fire brigade headquarters arrived and 35 fire fighting trucks were dispatched at 23:40. At 10:00 on August 13, 2015, Tianjin blast site rescue headquarters decided to suspend the rescue and determines what action to take after site survey. As at 11:00 on August 13, 2015, Tianjin fire brigade has deployed 143 fire engines and more than 1,000 fire fighters arrived at the scene rescue, but the specific explosives cannot be identified.

Tianjin Public Security Bureau firstly arrived at the scene and believed that the container was on fire, knowing nothing about the explosives. They take usual ways to put out the fire, for example, using water and foam. And many firefighters went near to dangerous chemicals. In the accident, in addition to great property losses, what is more important is that a large number of firefighters and hundreds of people injured or died in the two blasts after the fire [2]. The direct cause is that firefighters do not know the dangerous chemicals in the responsible zones. In the preparation phase of emergency management, one of the most important work is to know all potential disaster statistics point clearly within the areas under their jurisdiction, and formulate response plans accordingly, so that they can apply a more targeted approach to respond to the fire alarm.

\subsection{Untimely Safety Evacuation}

In emergency rescue, the timely evacuation to the residents surrounding the accident center area is a very important link of the government emergency management which can effectively prevent the occurrence of secondary disasters and avoid more casualties. In the August 12, Tianjin Port Explosion, chemical was exploded in large-scale, the evacuation of surrounding residents should be immediately organized by the emergency management. However, until 13th $5 \mathrm{pm}$, the 3 residential areas were evacuated and resettled. The affected area alert level is not high, the affected family were stolen endlessly, and some reporters even didn't wear gas masks in the accident site indicating that the danger area evacuation work needs to be strengthened in Tianjin City emergency management plan.

\subsection{Inconspicuous Security Zoning}

In the process of emergency management, putting the accident area as center, according to the affected areas gradually extend outward, reasonable dividing, as well as setting emergency center district, rescue areas and edge support areas, and emergency management to ensure that an important part of the rescue work effectively to carry out, can effectively prevent the occurrence of disasters in this life. The local government in the United States deals with large-scale emergencies usually with the alert area setting (see Figure 1) [3]. 


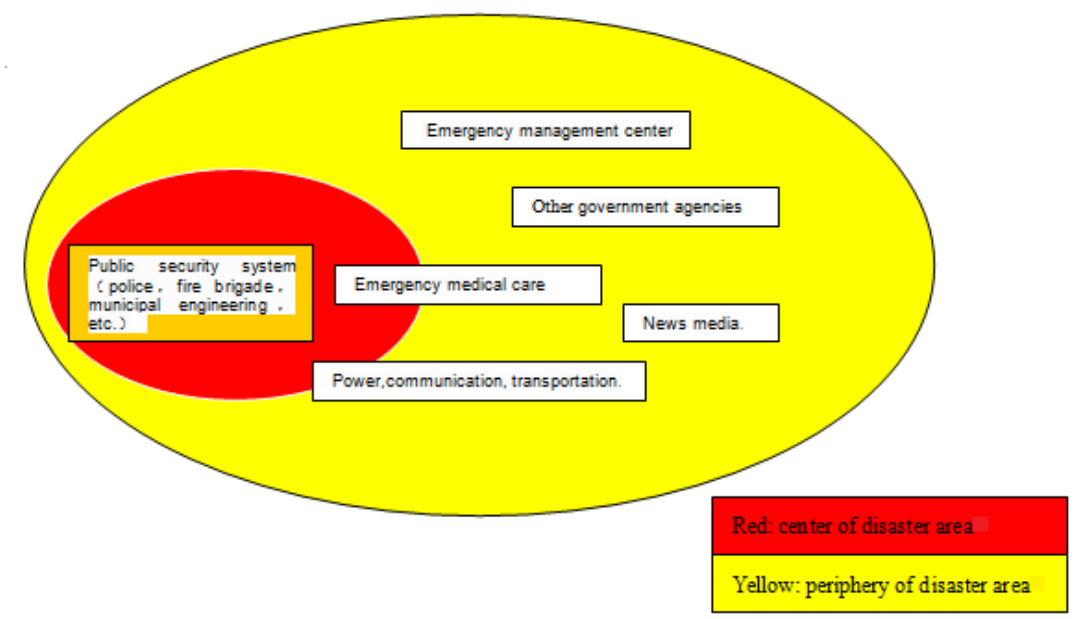

Figure 1. Setting of large scale emergency alert area

As shown in Figure 1, the event alert area consists of three areas: (1) the central area of the accident; (2) the accident rescue area; (3) the edge support area. Only front-line rescue workers can be allowed to enter the central area of the accident, the box area, and according to the accident rescue command center to carry out on-site rescue. Within the small round which in the outside area of that box area is the region for the accident rescue area where the rescue needed direct power, communications, transport workers and emergency ambulance men carry out rescue work. With the big round while outside the small round outside is the edge supporting area where decision-making command center, the news media and the resources of support units are set. Three regions are set in the alert area jointly where the martial law enforcement troops, armed police or police with law enforcement power should be set and keep alert to prohibit unrelated people trespassing, and have the responsibility of protecting the residents of the property.

\subsection{Insufficient Information Publication}

As for the major emergencies, timely official publication on the development of emergency response is the safeguard for the citizen's right to know, an important means to prevent rumors, properly treat bad social mood, stabilize social order. But after the Tianjin major fire and explosion the official press conference was too informal which seemed like was dealing with public and social media. Even several days after the accident occurred, the leaders in charge of the production safety and enterprises involved only met the media after prime minister. After the explosion the environmental protection department claimed that the detection of the various environmental indicators were normal, which be joked as "Was that the air freshener exposed?" in the Internet. The quite of Tianjin local media made people puzzled. In the era of new media, the whole media has been highly developed, this kind of passive, dodge, evasive and irresponsible behavior conversed to the block of trust between the people and government immediately. The famous media commentators Caolin thought that good media supervision can lead to a higher official response to public, however, the government who usually over control the media and simply put the local media as the mouthpiece, always seemed foolish when in the face of unexpected public events.

\subsection{Loopholes in the Disposition}

The explosion of Ruihai company in Tianjin Binhai New Area of dangerous goods warehouse, resulting in the damage of 12,500 imported cars which has not yet delivered, and some of which were completely burned. Unlike the destruction of the Japanese flood damaged vehicles, some of the damaged vehicles in the Tianjin explosion were flowed into the auction market through some channels [4]. These damaged cars contain great security hidden dangers, not just drivers and passengers are threatened, driving on public roads, once a traffic accident happen, it will directly pose a threat to the public security. The TIanjin government has the responsibility to require businesses to force the destruction of these damaged vehicles, and must not allow them to flow into the market through any channel. If they flow into the market, it must be forced to recover, and the involved 
business and personal should be dealt with according to law to avoid the secondary security incidents which threat public safety.

\section{The reflection of the Tianjin big fire accident}

In response to major emergencies, emergency management capability and the level of the government directly affect that whether the prevention and preparation before the accidents, the recovering loss during the accidents, and reconstruction after the accidents can be optimized. In the Tianjin port fire explosion accident, it is the government's poor emergency management capacity that leads to involved companies and government departments repeatedly out of the safety line. The non-compliance of national security laws and regulations is the major human factor of this explosion accident. Besides, firstly during the rescue, the fire department didn't get enough alert information, therefore the front-line firefighters in the rescue process were not clear about the specific fires caused by blindly rescue, resulting in the casualties of a large number of firefighters due to secondary explosion. Secondly, the government emergency management response the division of reasonable alert area were untimely, and fail to implement armed police troops to carry out accident area alert, therefore the surrounding areas were got into confusion, and the residents' property was stolen by lawbreakers. Third the government should enhance the ability to respond to the media and release official information timely in the emergency management process. Finally, the government should promptly investigate and deal with the accident, properly arrange reestablishment, without leaving the aftermath of the accident, to avoid secondary disasters occur again. According to Tianjin extra large fire and explosion accident, local governments must learn from their mistakes, serious reflect, and improve government emergency management capabilities from the following several aspects.

\subsection{Sticking to the principle of prevention first}

The saying goes "Preparedness ensures success, unpreparedness spells failure, preparedness also prevents calamity." In November 2007, the national level of "Measures Dealing with Emergencies Law"was formally promulgated and implemented, and also required local governments to develop and implement the similarly specific measures. Tianjin city, "the implementation of "the people's Republic of China's Methods Dealing with Emergency Law" promulgated the implementation in July 1, 2015, which is just the moment that Tianjin extra large fire and explosion accident occurred a month before, this time is already national "The Measures Dealing with Emergencies Law" promulgated and implemented in recent 8 years, 8 years of research develop a specific measures for the implementation of this should be more specific, more effective, according to the actual testing, Tianjin municipal government in emergency management there are many aspects to strengthen, still need to improve, just as on January 24, 2016, Tianjin mayor Huang Xingguo said in the government work report, "safety is the foundation of development and the largest livelihood. Tianjin port "812 "Ruihai company, the warehouse where stored the dangerous goods took place the fire explosion accident caused heavy casualties and property losses, the accident reflects the outstanding problems existing in the production safety in Tianjin city, in-depth implementation of "Safety Construction of Tianjin outline", fully implement the main responsibility, normative system, infrastructure construction, full security, information management and experts to inspect the " $5+1$ "safety supervision measures, with a resolute attitude to keep strict security red line[5].

\subsection{Upholding people as foundation}

The occurrence of unexpected events are bound to cause property damage, equipment damage or personnel casualties, especially like Tianjin Port 812 occurrence of dangerous chemicals catastrophic fire explosion and property on the greater threat, more destructive, often secondary disasters. Government in emergency management, facing the loss has occurred, the abandoned to give up, to ongoing damage to selectively rescue. The first principle is to save lives to adhere to the people-oriented, put people's life safety in the first place. Specifically at the scene of the accident, first of all, to guarantee the rescue team has its own security protection under the premise to carry out relief work, to fully protect the rescue personnel life safety, to give respect to the life of the rescuers also. 
Secondly, to evacuated the surrounding residents at the scene of the accident, to avoid secondary disasters causing more casualties among residents. Thirdly, to do a good job in the medical, health, life and other basic logistical support to protect the injured people get timely treatment; the affected people are properly placed. Finally, it is necessary to strengthen the affected population of post disaster psychological assistance.

\subsection{Adhering to the scientific rescue}

Blindly rescue often leads to secondary disasters, which results in secondary or multiple casualties, the more disastrous accident, the calm disposition requirements of government emergency management. To scientifically determine the potential risk, scientific decision-making, scientific rescue, the safety of rescue and do follow the progress in obedience to the quality and safety, and go all out to play a good rescue battle. First of all, let the science and technology experts think tank play their roles, provide intellectual support for the scientific rescue, scientific measures to rescue the specified. Secondly, focus on the role of the professional team of disaster relief role. Third, make full use of modern information network technology, equipment and technology advanced rescue equipment and equipment use and improve the efficiency of disaster relief.

\subsection{Persisting in the Unified Command}

The government organization is carved up, each of them does things separately. Lacking of coordination and unity of command is an important factor after a major disaster accident happened in which the emergency management can't play a role in emergency rescue efficiency. Emergency management is cross-border, which often across geographical boundaries and functional boundaries, in the emergency management of Tianjin port fire explosion accident, Tianjin City, Tianjin Binhai new area, Tianjin transportation committee, the game between the Tianjin port and the relevant departments of Tianjin resulted that many departments shirk responsibility and cannot have a coordination relationship. The Ruihai Company is located in Tianjin Ruihai port which belongs to Tianjin Binhai New Area in the administrative regionalization, but as the enterprises directly lead under the central government, the major department is The Ministry of Transport. Therefore, as the storage and transportation enterprises, Ruihai runs the hazardous chemicals, it's safe production and management is under the supervision of the port of Tianjin, and also by Tianjin Municipal Transportation Commission Member, Tianjin Municipal Production Safety Supervision and Management Bureau, Binhai New Area of Production Safety Supervision and Management Bureau, coastal district planning and management of Land Resources Bureau of supervision. Consequently, for the enterprises directly lead under the central government in the event of a major emergency accident which needs to be set up command center in the higher level, to break the fragmentation, to unite of command and coordination, to carry out emergency rescue and subsequent investigation of the cause in all functional departments.

\subsection{Insisting on Lawful Reply}

For emergencies, emergency management and disposal of government must be according to the law. "Safety Production Law", "Measures Dealing with Emergencies Law" and the specific methods of local governments is the legal basis for local governments to deal with emergencies. The most fundamental advance is to do a good job in security, in accordance with the laws and regulations of safety production supervision and inspection, examination and approval. According to the emergency disposal process and the blockade of dangerous places, designated warning area, the implementation of traffic control, severely punishing those who damage and disturb social order, maintain of public security; requisitioned units and individuals to sign with the necessary emergency rescue equipment, facilities, venues, transportation and other supplies. Afterwards to the aftermath of the law, the requisition of supplies, according to the law of payment or compensation, to investigate the cause of the accident in accordance with the law of accountability, the loss of the accident liability in accordance with the law for compensation. On the basis of Tianjin port explosion Bombing of the deal, the Binhai New District government need to negotiate with the owners of damaged houses, to buy back the damaged houses, whether the government buy back is reasonable or legitimate, there is a great controversy. 


\subsection{Making the Fire Brigade Professional}

China's current fire power is mainly by the public security fire troops, full-time fire brigade, voluntarily fire brigade forces system as a supplement. The fire team decides that it is always a young team, the team plays an important role in major emergencies and disaster relief, but it is after all composed of servicemen, facing the service time limit, firefighters, after the service period, will leave the fire team, which determines the current fire strength has always been in a state of flow between the old and the new, the flow state decides that after a certain training and exercise practice, the firefighters gained rich experience in actual combat, but they cannot be engaged in the actual work of the fire, the new firefighters often have poor experience for fire rescue which increases security risks. Therefore, China should learn the experience from developed countries, in the building of fire brigade, China should go after a professional direction, go a fire power professional road. In the UK, a specialized fire academy, from new into the position of firefighters to local fire officials need to come to school to receive training; Japan has a special fire school, players after strict training of vocational education, in order to become qualified firefighters; the United States also have about one-third of firemen belong to the career firefighters in the fire troop construction.

\section{Conclusion}

The massive blast of Tianjin on August 12ed is one of the largest safety production and fire protection incidents since the establishment of China, which caused numerous deaths and injuries, as well as great economic losses. It also reflects many problems of the government's emergency response in this accident, such as lacking of major pre-accident safety precautions, dealing with things in panic, blind and unscientific, after disposal loopholes. All alert the government that emergency management process should adhere to advance prevention, the principle of people-oriented, unified command, scientific rescue and response according to law in and after the accident, and take a professional road on building fire team.

\section{Acknowledgments}

This work was financially supported by "the National Social Science Foundation of China (13CGL132)", "the Fundamental Research Funds of National School of Administration (13HZKT199)", "the Scientific Projects of HuBei Province (2015BDF037)”.

\section{References}

[1] Information on http://news.china.com.cn/2015-09/12/content_36565776.htm.

[2] Information on http://news.china.com.cn/2015-09/12/content_36565776.htm.

[3] Information on http://blog.sina.com.cn/s/blog_69b9a00b0102vw5d.html.

[4] Information on http://news.ifeng.com/a/20160123/47195693_0.shtml.

[5] Information on http://n.cztv.com/news/11896196.html. 